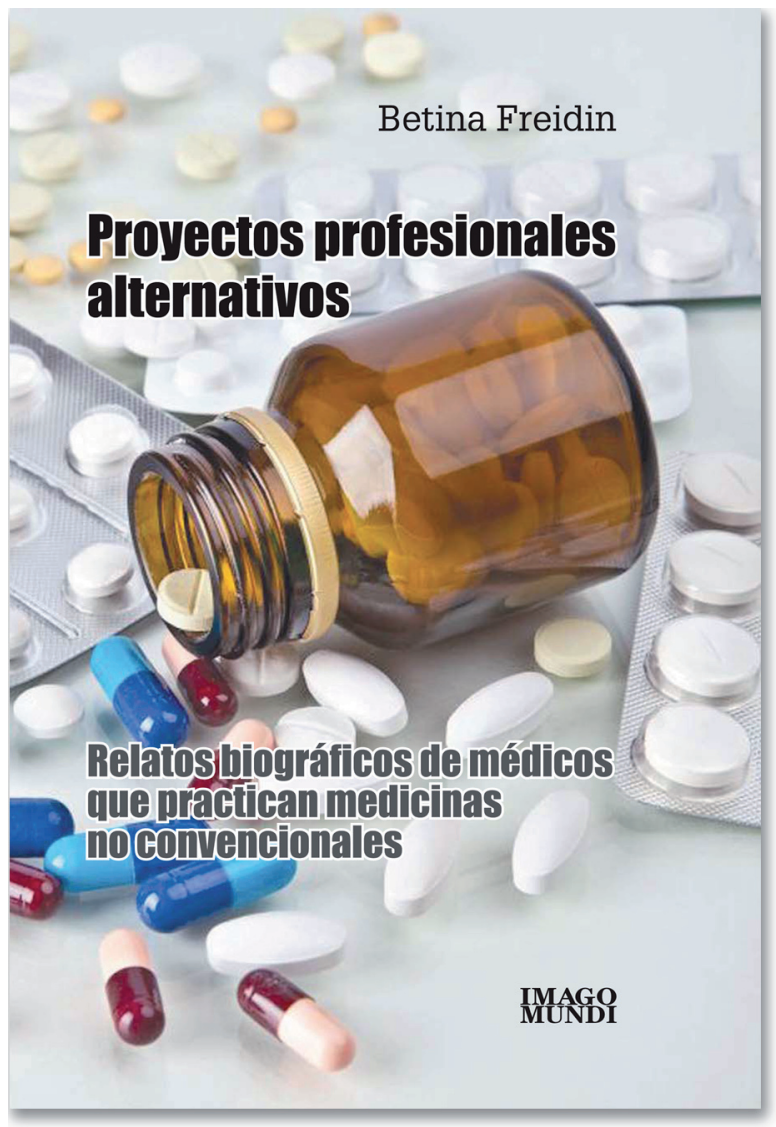

\title{
Reseña: Proyectos profesionales alternativos - Relatos biográficos de médicos que practican medicinas no convencionales
}

\author{
Book Review: Alternative professional \\ projects - Biographical accounts of doctors \\ who practice non-conventional medicine
}

\begin{abstract}
Betina Freidin. Proyectos profesionales alternativos - Relatos biográficos de médicos que practican medicinas no convencionales. Buenos Aires: Ediciones Imago Mundi; 2014. 128 páginas. ISBN: 978-950-793-188-8.
\end{abstract}

\section{Esteban S. Grippaldi}

En un contexto de ampliación de las modalidades terapéuticas, Argentina dispone de un conjunto creciente de estudios sobre difusión y utilización de medicinas alternativas. Esta producción de conocimientos tiende a enfocar su objeto de investigación en pacientes y en especialistas sin formación en biomedicina. En su reciente libro, la socióloga y doctora en Ciencias Sociales Betina Freidin ${ }^{[a]}$ centra su mirada en un fenómeno escasamente abordado en el ámbito nacional. De este modo, la autora indaga de manera original en los recorridos biográficos y en las perspectivas de médicos alópatas que se desvían del ejercicio convencional de la profesión para practicar medicinas alternativas y complementarias ${ }^{[\mathrm{bl}]}$.

El libro, fruto de una investigación empírica en el área de sociología de la salud, está dirigido a un público académico. El objeto de estudio de su investigación, tal como Freidin lo expresa en las primeras páginas, lo constituye un grupo de "médicos heterodoxos"(1 p.3), particularmente, aquellos profesionales practicantes de la homeopatía, acupuntura y medicina ayurvédica en el Área Metropolitana de Buenos Aires (AMBA). La socióloga destaca tres objetivos de investigación que, estrechamente vinculados entre sí, estructuran las argumentaciones centrales del libro. En este sentido, propone dar cuenta de, en primer lugar, "las circunstancias personales y experiencias profesionales" que conducen a este grupo de profesionales a interesarse en estas medicinas alternativas; en segundo lugar, "el impacto de dicho interés en la vida e identidad profesional" y, por último, "las diversas modalidades de su incorporación en distintos contextos de práctica profesional"(1 p. 17). Ahora bien, ¿cuál es la estrategia de investigación mediante la cual la autora construye y aborda estos objetivos?

Para el estudio de los profesionales heterodoxos, Freidin parte de una perspectiva teórica constructivista. Específicamente, asume los postulados del interaccionismo simbólico y

'Licenciado en Sociología. Doctorando en Ciencias Sociales, Universidad de Buenos Aires. Becario doctoral, Consejo Nacional de Investigaciones Científicas y Técnicas (CONICET), con sede en Universidad Nacional del Litoral, Santa Fe, Argentina. $₫$ (iD) 
enfatiza el interés en la construcción de significados desde el punto de vista de los actores. Esta clave analítica permite indagar y comprender los procesos de construcción de identidades y la adquisición de nuevos saberes profesionales. Esta concepción teórica está vinculada de forma indisociable a una estrategia metodológica, y con ambas la autora construye y aborda los objetivos de investigación.

Coherente a los supuestos del interaccionismo simbólico, Freidin utiliza un enfoque metodológico cualitativo con orientación biográfica. De este modo, mediante los relatos biográficos, identifica los puntos de inflexión, las tensiones con el paradigma biomédico, las crisis, los obstáculos en la implementación de nuevas prácticas y experiencias transformadoras a lo largo de la vida profesional de los entrevistados. La muestra del estudio está conformada por un total de 42 entrevistas semiestructuradas, realizadas en igual cantidad a hombres y mujeres. El criterio de selección de los entrevistados consistió en que fueran médicos de diferentes especialidades alopáticas que practicaran medicinas alternativas no convencionales -homeopatía, acupuntura y ayurveda- en el AMBA. Además, para la selección de casos, la socióloga buscó la diversidad etaria. Este criterio permite recuperar, a través de los relatos, diversas experiencias de médicos graduados en distintas décadas, lo que implica que hayan integrado diferentes momentos históricos del campo de la salud.

Producto de los objetivos propuestos, el foco analítico de la investigación está localizado, centralmente, en el plano microsocial. Pero el anclaje en esta dimensión no conduce a descuidar los vínculos con las dimensiones meso y macro que guarda su objeto de estudio. Así, recurrentemente, para comprender las experiencias e itinerarios de profesionales heterodoxos, Freidin enmarca las voces de los actores en el contexto sociocultural e histórico más amplio en el cual se insertan. Respaldada por estudios actuales tanto de Argentina como de diversos países sobre el campo médico, la autora sostiene que, en las sociedades contemporáneas, producto de un proceso histórico de amplio alcance no exento de conflictos, la biomedicina establecida en el sistema médico dominante coexiste cada vez más con enfoques holísticos y terapias alternativas. En el contexto de la modernidad tardía, se registra un marcado aumento de las opciones de cuidado de la salud por parte de los especialistas y los usuarios, acompañado de un cuestionamiento de los saberes expertos del paradigma biomédico biologicista, sustentado en la racionalidad científica occidental. Por tanto, en el escenario actual, caracterizado como "pluralismo terapéutico"(1 p. 4), se asiste a la difusión de terapias alternativas y complementarias $y$, en este trasfondo sociohistórico, adquiere un valor central recuperar los testimonios de los profesionales heterodoxos interesados en conocer y practicar modalidades más integrales y humanizadas de tratamiento.

Ahora bien, ¿de qué dan cuenta los relatos biográficos de los entrevistados? Los diversos testimonios no ofrecen una respuesta univoca. Uno de los méritos principales del libro es describir el complejo escenario desde las perspectivas y experiencias de los médicos heterodoxos sin simplificar las diversas miradas y posicionamientos. Así, lejos de hacer de las múltiples voces una única visión, como si se tratase de un grupo homogéneo, la autora reconstruye las diferentes trayectorias y relatos de los médicos practicantes de medicinas no convencionales, contrastándolas entre sí, lo que pone en evidencia diferencias significativas en su interior.

Para dar cuenta del distanciamiento con respecto a la práctica de la medicina convencional, los entrevistados entretejen un variado conjunto de razones entre las que se acentúan aquellas de índole profesional, "principalmente frustraciones en la etapa de formación y experiencias laborales insatisfactorias en el mercado de trabajo médico, así como oportunidades de formación de posgrado en medicinas alternativas y complementarias con respaldo universitario", y personales, "búsquedas espirituales y experiencias personales"(1 p.85) como, por ejemplo, intentar aliviar malestares. Asimismo, la postura que adoptan con respecto al modelo biomédico adquiere diversas modalidades. Mientras que, de un lado, un conjunto de testimonios busca ampliar los recursos terapéuticos mediante las medicinas alternativas,

Salud Colectiva | Licencia Creative Commons Reconocimiento - No Comercial 4.0 Internacional | BY - NC 
en el otro extremo, algunos establecen un alejamiento más radical, producto de experimentar

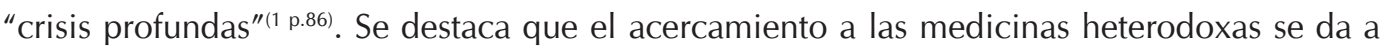
través de vínculos profesionales e informales en la formación de grado y posgrado; la familia de origen; una incursión paralela a la formación en biomedicina, en busca de alivio a padecimientos personales o búsquedas espirituales. Además, si bien la mayoría de los entrevistados integra más de una medicina alternativa en su práctica profesional, se evidencian diferencias entre aquellos que buscan ampliar los recursos terapéuticos y quienes tienden a especializarse en un enfoque heterodoxo.

A pesar de la diversidad de voces, la autora no deja de reconocer concordancias entre los médicos que practican medicinas no convencionales. La base común de este grupo, a partir de la cual construyen sus identidades profesionales como médicos heterodoxos, está formada por la elaboración de una postura crítica respecto del modelo médico ortodoxo. Más allá de las diferencias en los caminos biográficos, experiencias y razones, el trasfondo compartido que atraviesan los relatos es la necesidad de reconciliación con el ejercicio de la profesión, a través de las medicinas alternativas y complementarias.

En cuanto al modo de exposición, el libro posee una estructuración lógica y coherente. En las primeras páginas Freidin fundamenta los principales componentes de la investigación, dando cuenta de los antecedentes sobre la temática, los objetivos, la perspectiva analítica, la estrategia metodológica y las directrices del trabajo de campo. En los dos capítulos siguientes aborda, en estrecha sintonía con los objetivos de investigación, los resultados alcanzados. Así, en el capítulo 2 describe los diversos "caminos biográficos", la trama de motivaciones y razones, experiencias personales y profesionales que conducen a médicos de formación ortodoxa a practicar medicinas no convencionales. En el capítulo 3 desarrolla, principalmente, las distintas formas en las que los entrevistados practican las medicinas alternativas y los ámbitos de trabajo donde desempeñan sus actividades. En la conclusión retoma las líneas centrales de la argumentación. En pocas páginas, la autora logra condensar y hacer inteligibles los distintos aspectos desarrollados a lo largo del libro. Por último, en el "Anexo" describe brevemente el desarrollo de la homeopatía, la acupuntura y el ayurveda en Argentina, y considera centralmente la difusión en los círculos médicos, los procesos de institucionalización y los aspectos regulatorios. En su escritura se destaca el uso adecuado de citas de los entrevistados, las cuales permiten esclarecer e ilustrar el desarrollo de razonamientos.

El libro de Freidin constituye un valioso aporte de conocimiento empírico sobre las perspectivas y experiencias de médicos que formados en la medicina convencional reorientan sus prácticas hacia las medicinas alternativas y complementarias, en un escenario enmarcado en el pluralismo terapéutico. Freidin conduce al lector a adentrarse y comprender los universos de sentido de estos practicantes disidentes del ejercicio convencional de la medicina respecto de las formas de identificación con la profesión, las tensiones y obstáculos que experimentan en su trabajo cotidiano, y las diferencias con la biomedicina. En un contexto cultural de ampliación de las modalidades terapéuticas, visibiliza voces críticas al modelo médico hegemónico de sujetos socializados en su interior y resalta, a través de una mirada original, una línea de trabajo desatendida en el área nacional, que permite abrir nuevos horizontes de indagación e interpretación. 


\section{REFERENCIAS BIBLIOGRÁFICAS}

Freidin B. Proyectos profesionales alternativos: Relatos biográficos de médicos que practican medicinas no convencionales. Buenos Aires: Ediciones Imago Mundi; 2014.

\section{NOTAS FINALES}

[a] La investigación que dio origen al libro fue financiada a través del Consejo Nacional de Investigaciones Científicas y Técnicas (CONICET) mediante el proyecto de investigación titulado
"La práctica de la medicina integrativa en Argentina". Betina Freidin es licenciada en Sociología y magíster en Investigación Social por la Universidad de Buenos Aires. La autora, además, es investigadora independiente del CONICET y doctora en Sociología, por la Brandeis University, Massachusetts, EE.UU.

[b] Se utilizarán de manera indistinta los términos medicinas alternativas, medicinas alternativas y complementarias, medicinas no convencionales y heterodoxias médicas, del mismo modo que lo hace Freidin en el libro aquí reseñado.

FORMA DE CITAR

Grippaldi ES. Reseña: Proyectos profesionales alternativos - Relatos biográficos de médicos que practican medicinas no convencionales. Salud Colectiva. 2012;12(2):307-310. doi: 10.18294/sc.2016.890.

Recibido: 22 de marzo de 2016 | Aprobado: 11 de mayo de 2016

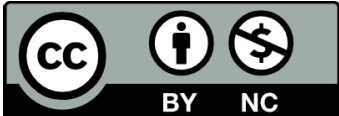

Este obra está bajo una licencia de Creative Commons Reconocimiento-NoComercial 4.0 nternacional. Reconocimiento - Permite copiar, distribuir y comunicar públicamente la obra. A cambio, se debe reconocer y citar al autor original. No Comercial - Esta obra no puede ser utilizada con finalidades comerciales, a menos que se obtenga el permiso. 